\title{
Efeito comportamental em modelos experimentais de depressão por microinjeções do peptídeo liberador de gastrina via intra nucleus accumbens
}

Behavioral effect in experimental models of depression by gastrin releasing peptide microinjection via intra nucleus accumbens

Efecto conductual en modelos experimentales de depresión mediante microinyección de péptidos liberadores de gastrina a través del núcleo accumbens

Rodrigo de Almeida - https://orcid.org/0000-0002-0699-7871 Jorge Henna Neto - https://orcid.org/0000-0003-4382-4299 Eduardo Ernani Piazza da Silva - https://orcid.org/0000-0001-6161-3597

\section{RESUMO:}

Introdução: O Transtorno Depressivo Maior é uma condição médica comum na população, que pode atingir não somente a capacidade mental, mas também a capacidade física, causando inclusive incapacidade laboral. A sua causa ainda permanece desconhecida, apesar de algumas teorias terem ganhado espaço, como as hipóteses da neurogênese e da neuroplasticidade, que surgiram num contexto onde a clássica hipótese das monoaminas já não explica todos os casos. Nesse contexto, uma forte associação entre a hiperatividade do eixo hipotálamo-pituitária-adrenal, bem como dos hormônios do trato gastrointestinal, foram destacados em estudos, levantando a hipótese de a depressão ter fatores metabólicos associados, levando inclusive a caracterização de doença metabólica segundo alguns autores. Objetivos: Desta forma, o presente estudo busca analisar o feito comportamental do hormônio do trato gastrointestinal GRP tendo em vista as evidências presentes sobre a possível relação deste com a fisiopatologia da depressão. Método: Foram selecionados 20 camundongos Swiss para realização do procedimento da derrota social, análise com teste do nado forçado e intervenção com Fluoxetina no 
controle e GRP no experimental. Resultados: O estresse de derrota social aumentou o tempo de imobilidade no teste do nado forçado em 13 segundos nos camundongos submissos, a injeção de GRP reduziu o tempo de imobilidade com uma diferença de 78 segundos para o grupo controle tratado com Fluoxetina. Conclusão: Assim, o GRP, comparado aos outros hormônios estudados na depressão apresentou efeito positivo no quadro depressivo e possível terapia para seu tratamento.

Palavras-chave: Transtorno Depressivo Maior; Depressão; GRP.

\section{ABSTRACT:}

Introduction: Major Depressive Disorder is a common medical condition in the population, which can affect not only mental capacity, but also physical capacity, even causing incapacity for work. Its cause is still unknown, although some theories are gaining ground, such as the neurogenesis hypotheses as well as the neuroplasticity hypothesis, which emerged in a context where the classic monoamine hypothesis no longer explains all cases. In this context, a strong association between hyperactivity of the hypothalamic-pituitary-adrenal axis as well as gastroin-testinal tract hormones was highlighted in studies raising the hypothesis that depression has associated metabolic factors, even leading to the characterization of metabolic disease ac-cording to some authors. Objective: Thus, the present study seeks to analyze the behavioral effect of the gastrointestinal tract hormone GRP in view of the present evidence on its possible relationship with the patho-physiology of depression. Methods: Twenty Swiss mice were selected to perform the social defeat procedure, analysis with forced swimming test and intervention with Fluoxetine in the control and GRP in the experimental. Results: Social defeat stress increased the immobility time in the forced swim test by 13 seconds in the submissive mice, the GRP injection reduced the immobility time with a difference of 78 seconds for the control group treated with Fluoxetine. Conclusion: Thus, GRP, compared to other hor-mones studied in depression, had a positive effect on depres-sion and a possible therapy for its treatment.

Keywords: Major Depressive Disorder; Depression; GRP 


\section{RESUMEN:}

Introducción: El Trastorno Depresivo Mayor es una condición médica común en la población, que puede afectar no solo la capacidad mental, sino también la física, llegando incluso a causar incapacidad para el trabajo. Su causa aún se desconoce, aunque van ganando terreno algunas teorías, como las hipótesis de la neurogénesis y la hipótesis de la neuroplasticidad, que surgieron en un contexto donde la hipótesis clásica de las monoaminas ya no explica todos los casos. En este contexto, se destacó una fuerte asociación entre la hiperactividad del eje hipotalámico-pituitario-adrenal y las hormonas del tracto gastroin-testinal en estudios que plantean la hipótesis de que la depresión tiene factores metabólicos asociados, llegando incluso a caracterizar la enfermedad metabólica según a algunos autores. Objetivo: De esta manera, el presente estudio busca analizar el efecto conductual de la hormona GRP del tracto gastrointestinal a la vista de la evidencia actual sobre su posible relación con la fisiopatología de la depresión. Métodos: Se seleccionaron veinte ratones suizos para realizar el procedimiento de derrota social, análisis con prueba de nado forzado e intervención con Fluoxetina en el control y GRP en el experimental. Resultados: El estrés por derrota social aumentó el tiempo de inmovilidad en la prueba de nado forzado en 13 segundos en los ratones sumisos, la inyección de GRP redujo el tiempo de inmovilidad con una diferencia de 78 segundos para el grupo de control tratado con fluoxetina. Conclusión: Así, el GRP, en comparación con otras hormonas estudiadas en la depresión, tuvo un efecto positivo sobre la depresión y una posible terapia para su tratamiento.

Palabras clave: Trastorno Depresivo Mayor; Depresión; GRP

Como citar: Almeida R, Henna J, Piazza E. - Efeito comportamental em modelos experimentais de depressão por microinjeções do peptídeo liberador de gastrina via intra nucleus accumbens. Debates em Psiquiatria, Rio de Janeiro, 2021; 11:1-26.

https://doi.org/10.25118/2763-9037.2021.v11.221 
Conflito de interesses: declaram não haver

Fonte de financiamento: declaram não haver

Parecer CEP: Parecer CEUA/PUC-SP (Uso de Animais): Protocolo no 2019/111.

Recebido em: 18/10/2021

Aprovado em: 02/12/2021

Publicado em: 03/12/2021

\section{Introdução}

O Transtorno Depressivo Maior (TDM) é uma condição médica comum na população, que pode atingir, não somente a capacidade mental, mas, também, a capacidade física, causando, inclusive, incapacidade laboral. A World Health Organization (WHO) traz em seu estudo que TDM é um dos mais prevalentes transtornos mentais, atingindo mais de 322 milhões de pessoas no mundo, equivalente a $4,4 \%$ da população mundial [1] .

Embora historicamente a depressão tenha associação com disfunções da serotonina (5-HT) e circuitos contendo norepinefrina, pesquisas mais recentes utilizando neuroimagem, métodos farmacológicos e eletrofisiológicos em humanos e modelos animais de depressão, forneceram suporte para a presença de disfunções do sistema de dopamina. Desse modo, concluiu-se que a depressão e a anedonia demonstraram estar associadas a uma resposta estriada reduzida do sistema de recompensa [1] .

Não obstante, há estudos que, também, associam a depressão ao estresse. O estresse agudo pode ser adaptativo, o estresse crônico pode ser biologicamente prejudicial, fazendo-se um fator relevante no 
desenvolvimento da depressão. O estresse promove adaptações centrais $\mathrm{e}$ periféricas em sistemas corporais via eixo hipotálamo-hipófise-adrenal (HPA), que se alimenta no cérebro através de liberação de corticosteróides.

Em estudo experimental com roedores, o estresse repetido a partir da estimulação de estruturas excitatórias do prosencéfalo incluindo o hipocampo, amígdala e córtex pré-frontal, entre outras regiões que medeiam a memória emocional e ansiedade, resultou em déficits dramáticos na sinalização excitadora local e eferente para regiões de integração, como o núcleo accumbens [2]]. Inclusive, o núcleo accumbens é a entrada excitatória que desencadeia, emocionalmente, comportamentos motivados através de laços talâmicos corticostriais dentro dos gânglios basais, sendo que, eventualmente, conduz o estriado dorsolateral para facilitar os comportamentos relacionados à ação []].

Além disso, a dopamina é um importante neurotransmissor do núcleo accumbens. Nos modelos animais de depressão, o sistema de dopamina é "downregulated", medido por uma diminuição no número de neurônios do sistema de dopamina que disparam espontaneamente. Esta diminuição se deve a hiperatividade da sub-região infra límbica, dirigindo atividade na via inibidora da amígdala basolateral-ventral pallidum enquanto atenua a excitação através do subiculum ventral do hipocampo, nucleus accumbens e ventral pallidum []ㅡ.

Apesar da visão da depressão como uma doença psiquiátrica clássica, múltiplas evidências apontam para a doença com um forte fator metabólico associado. Segundo estudo, uma em cada três crianças nos Estados Unidos da América (EUA) vão desenvolver diabetes Mellitus tipo 2 (DM2) durante 
a suas vidas [4]. A prevalência no Brasil chega a ser de 7,5\%, sendo que cerca de $50 \%$ da população diabética desconhece ter a doença [ $\underline{5}$ ].

Dessa forma, juntando essas informações com o fato de que a depressão é altamente associada, não somente a DM2, como, também, a obesidade e síndrome metabólica tem-se uma relação alarmante. Em um estudo realizado ainda nos EUA, sintomas depressivos foram documentados em $12,8-29 \%$ dos homens e $23.8-30,5 \%$ das mulheres com DM2 recém diagnosticada []].

O estresse crônico parece estar relacionado com toda a cascata de eventos responsável pelo desenvolvimento da depressão bem como as demais consequências sistêmicas da hiperativação do eixo HPA, que levariam a desregulação do sistema nervoso autônomo (SNA). Com isso, tem-se um envolvimento sistêmico da doença, podendo ter consequências diretas e indiretas como cardiovasculares, renais, do sistema nervoso central, sistema imunológico e do trato gastrointestinal (TGI) $[\underline{Z}, \underline{8}]$. Nesse contexto, foi levantada a hipótese sobre o efeito humoral dos hormônios gastrointestinais dentro do quadro depressivo.

Em modelos de estresse crônico utilizando protocolo de derrota social foi demonstrada elevação dos níveis séricos de grelina pela ativação do SNA, sendo essa uma resposta adaptativa, uma vez que os níveis elevados de grelina resultaram em alterações comportamentais ansiolíticas e antidepressivas []].

O fator de crescimento semelhante a insulina IGF-1 tem sido relacionado, também, pelo seu efeito regulador positivo sobre a neurogênese 
hipocampal [10], tendo ainda efeitos antidepressivos $[\underline{11}, \underline{12}] . A$ colecistoquinina ( $\mathrm{CCK}$ ) também se eleva em resposta ao estresse crônico provocado por meio do protocolo de derrota social [13]. A inibição dos receptores de CCK também demonstraram efeitos antidepressivos associados a reversão do eixo HPA em camundongos [프, 14-16].

O peptídeo liberador de gastrina (GRP) também se apresenta promissor para o tratamento da depressão, pois estudos descrevem ampla presença de receptores do GRP (GRPRs) no SNC em locais como bulbo olfatório, amígdala central, hipocampo dorsal e núcleo accumbens [17], cuja sua expressão alterada pode estar relacionada com doenças psiquiátricas relacionadas ao stress como a depressão $[\underline{18}, \underline{19}]$. Estudos farmacológicos e genéticos em roedores demonstraram que o GRP em áreas como o hipocampo e amígdala estão envolvidos na plasticidade sináptica além de estar relacionado com comportamento depressivo, ansiedade e estresse $[\underline{20}-\underline{23}]$.

O objetivo desse estudo é identificar os resultados da aplicação farmacológica da proteína GRP em modelos experimentais com depressão.

\section{Metodologia}

\section{Animais}

Foram selecionados 20 camundongos machos Swiss Webster adultos de 40 dias $[\underline{24}, \underline{25}]$, provenientes do biotério da Faculdade de Ciências Médicas e da Saúde da PUC- SP (FCMS, PUC/SP). Foram acondicionados em gaiolas contendo até 5 animais cada, mantidas em ambiente de temperatura controlada $\left(25^{\circ} \mathrm{C} \pm 2{ }^{\circ} \mathrm{C}\right)$ e expostos a luz por um período diário de 12 
horas (7:00 - 19:00h). Os animais terão acesso ad libitum a ração comercial.

Após a chegada, os animais foram aclimatados durante 1 semana antes do uso em procedimentos experimentais. Os animais foram introduzidos na sala do experimento pelo menos $1 \mathrm{~h}$ antes dos testes comportamentais.

O presente Projeto de IC foi submetido para avaliação Comissão de Ética em Pesquisa no Uso de Animais (CEUA) da FCMS-PUC/SP, n02019/111.

\section{Grupos}

Os animais foram divididos em 2 grupos, descritos a seguir conforme a tabela de procedimentos posterior:

Grupo A: Grupo adulto de controle com tratamento via Fluoxetina.

Grupo B: Grupo adulto experimental com tratamento via GRP.

\section{Teste do Tubo}

O Teste do Tubo foi realizado a partir de um tubo feito de material transparente, consistindo em, aproximadamente, $3 \mathrm{~cm}$ de diâmetro e $30 \mathrm{~cm}$ de comprimento. O procedimento é dividido em três etapas, sendo as duas primeiras de adaptação do camundongo Swiss Webster ao tubo e, a última etapa, o teste entre os camundongos.

\section{Habitação:}

Consiste em habituar os camundongos com os tubos, evitando eventos de ansiedade e estresse. Assim, o tubo é colocado na gaiola, por alguns minutos com cada camundongo, 3 dias antes do início do teste em si. 


\section{Treinamento:}

Objetiva a familiarização dos camundongos com o teste, principalmente o evento de caminhar durante o tubo até seu fim. Desse modo, pode começar a ser realizado 2 dias antes do começo dos testes, durante 10 minutos por camundongo.

\section{Teste do Tubo:}

É feito com pares de camundongos por pelo menos 4 dias, cada teste do tubo deve durar até 2 minutos, devendo ser interrompido após esse tempo. Após a sua realização, cada camundongo deve voltar para a sua gaiola por pelo menos 2 minutos antes de realizar outro teste, reduzindo os efeitos de derrota e vitória no teste anterior. Tal teste deve ser feito com os camundongos da mesma gaiola de forma randomizada e realizar uma classificação após o tempo de teste estipulado, maior ou igual a 4 dias.

\section{Protocolo de estresse de derrota social}

Conforme protocolo já existente [24-27], cada camundongo Swiss Webster macho dominante foi colocado em uma gaiola sozinho com comida e água ad libitum. Após um período de 10 dias, foi colocado um dos machos submissos, selecionados no Teste do tubo, com contato físico com o camundongo dominante durante 10 minutos. Os movimentos foram monitorados e contabilizado o número de ataques ocorridos nesse ínterim ao total de 10 dias de teste.

\section{Procedimentos cirúrgicos}

No dia do experimento os animais foram submetidos a sedação com Ketamina base - 50mg/ml (KetalarR- Cristalia do Brasil) numa dose de 
aproximadamente $4 \mathrm{mg} / \mathrm{kg}$, por via intramuscular, associada a Xilazina $10 \mathrm{mg} / \mathrm{ml}$ (CoopazineR- CoopersBrasil Ltda.) numa dose de 0,04 mg/kg, também por via intramuscular aplicado na musculatura lateral da coxa com seringa de insulina e agulha 20G. Essas drogas associadas provocam um efeito sedativo que dura em torno de 1 hora, tempo suficiente para realização da cirurgia.

Os animais foram implantados estereotaxicamente. O crânio foi exposto e um buraco de trepanação foi feito com broca dental salina refrigerada com cânulas de guia de aço inoxidável bilaterais de calibre 21 posicionadas acima da NAcc medial posterior (AP $+1,4 \mathrm{~mm}, \mathrm{ML} \mathrm{0,6} \mathrm{mm} \mathrm{do} \mathrm{bregma} \mathrm{e} \mathrm{DV}$ $-4,7 /-4,2$ da superfície do crânio), conforme coordenadas préestabelecidas [료 $\underline{30}$ ]. Foram utilizados três parafusos de aço inoxidável e cimento dental para ancorar a cânula no crânio.

O escalpo foi suturado e lidocaína gel foi aplicada na ferida de todos os grupos. Os animais foram então removidos do quadro estereotáxico e retornaram às suas respectivas gaiolas para se recuperarem da anestesia, foi feita a antissepsia crânio do animal com álcool a 70\% e isolado por campo estéril fenestrado. Os materiais utilizados no procedimento são todos esterilizados em sistema de autoclave.

Os animais foram recuperados durante oito dias e receberam parto acetaminofeno $(50 \mathrm{mg} / \mathrm{kg}$ ) retal durante os quatro primeiros dias, durante os quais foram alojados individualmente, manipulados e aclimatados ao procedimento de injeção. 
As doses utilizadas de solução salina e GRP tem como base o estudo de James Flood e John Morley [21] , que estudaram os efeitos dos hormônios gastrointestinais na memória e a neurofisiologia resultante após a sua liberação. Além disso, eles analisaram a quantidade de GRP necessária para ter efeito na retenção e estimulação da memória de modelos experimentais.

\section{Infusão intracerebral de solução salina}

Foi infundida 2[micro]l de solução salina a 0,9\%, conforme estudo [21].

\section{Infusão intracerebral de GRP}

Foi infundido GRP numa dose 2,5[micro]g diluídos numa solução salina de 2 [micro]l a 0,9\%, conforme estudo [21].

\section{Tratamento antidepressivo comprovado}

O tratamento foi feito conforme estudo prévio (24), foi administrada fluoxetina com dose de $20 \mathrm{mg} / \mathrm{kg}$ por via intraperitoneal por 28 dias.

\section{Teste do nado forçado (TNF)}

O TNF foi feito conforme protocolo já pré-estabelecido para modelos experimentais de depressão que consiste na submissão dos animais a uma sessão de nado forçado de 6 minutos de duração, divididas entre pré-teste (primeiros 2 minutos) e teste (últimos 4 minutos). Para a realização do nado, os animais foram colocados individualmente em um cilindro (altura $=50 \mathrm{~cm}$; diâmetro $=25 \mathrm{~cm}$ ) contendo $30 \mathrm{~cm}$ de água na temperatura de $25^{\circ} \mathrm{C} \pm 1^{\circ}$ de onde não conseguiam escapar e nem se apoiar no fundo do cilindro. O aumento do tempo de imobilidade, em relação ao grupo controle, foi interpretado como comportamento depressivo [르]. 
A análise comportamental foi feita por meio do software Behavioural Monitoring Tool, [31] um programa open source, o qual é usado para monitorização do comportamento de modelos experimentais por meio de uma câmera.

Os resultados foram analisados e classificados conforme o comportamento de: (1) Imobilidade - em que o animal fica parado, sem deslocamento do corpo pela água. Pode realizar movimentos leves necessários para manter a cabeça fora da água; (2) Nado - o animal realiza movimentos rápidos com as patas dianteiras horizontalmente, se deslocando ou não pelo cilindro; (3) Escalada - o animal realiza movimentos rápidos com as patas dianteiras se deslocando verticalmente pelo cilindro; (4) Mergulho - o animal mergulha, permanecendo com o corpo totalmente submerso.

\section{Cronograma dos procedimentos}

Os procedimentos foram realizados em 49 dias sendo o primeiro dia "D1" e o último dia "D49", a seguir:

D1 - D10: Condicionamento operante, Teste do Tubo, Aclimatamento;

D11-D20: Teste do nado forçado 1, Protocolo de estresse de derrota social, Teste do nado forçado 2;

D21: Procedimentos cirúrgicos;

D22-D49: Teste do nado forçado 3, Tratamento com fluoxetina (grupo controle).

\section{Resultados}

\section{Seleção dos dominantes}

Os 20 camundongos Swiss adultos machos estavam alojados em 4 gaiolas 
com 5 animais em cada uma. Foi realizado o Teste do Tubo, seguindo todos as etapas do protocolo, em duas etapas. Na primeira, o teste foi feito com os animais habitados em cada gaiola em busca dos 2 camundongos mais dominantes em cada uma, sendo encontrados 8 camundongos ao final dessa etapa. Posteriormente, novo teste foi realizado com os camundongos selecionados para estabelecer uma hierarquia de dominância entre os camundongos.

Os 4 camundongos mais dominantes foram aclimatados nas 4 gaiolas por 10 dias individualmente com serragem e alimentação e hidratação ad libitum; por outro lado, os restantes ficaram alojados juntos em outras 4 gaiolas menores com 4 animais em cada compartimento, com as mesmas condições que os camundongos dominantes.

\section{Teste do Nado Forçado 1}

Foi realizado um teste inicial do Nado Forçado antes da realização do Protocolo de Estresse social, seguindo a metodologia. Nesse teste, cada camundongo foi monitorado individualmente e as informações tabeladas no Kinoscope. A média de tempo de Imobilidade foi de 136,049 segundos $(112,406$ - 153,883) foi maior que as outras ações dos camundongos no decorrer do teste (Gráfico 1), sendo que o tempo estudado foram os 4 minutos finais, sendo após os 2 minutos iniciais de adaptação dos animais ao procedimento. Durante o estudo, foram identificados, além da Imobilidade, outras ações de Escalada, com média de 36,925 segundos $(7,092$ - 69,367) e a Natação, com média de 67,025 segundos ( 22,250 $86,932)$. 


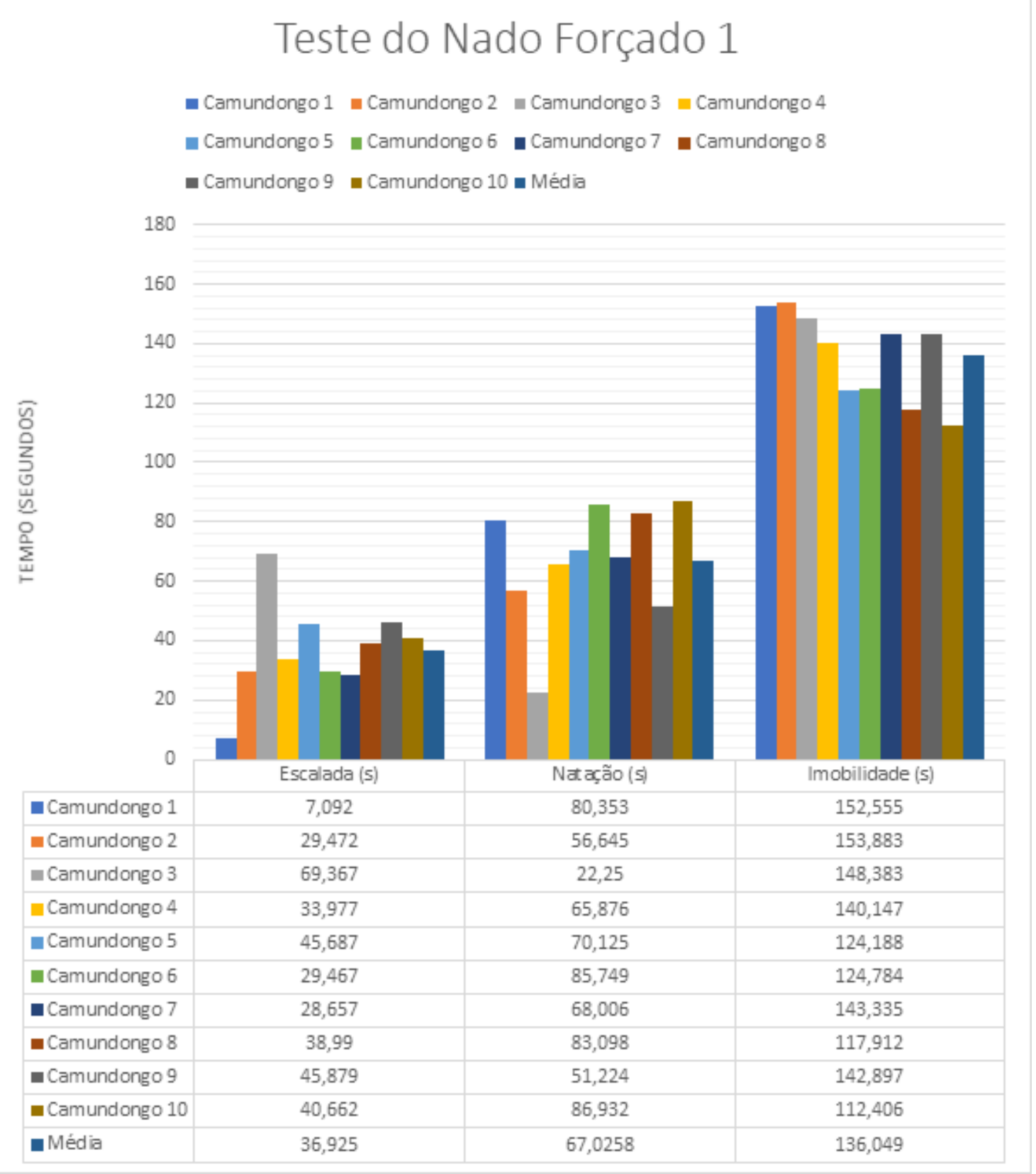

Gráfico 1. Primeiro Teste do Nado Forçado.

\section{Estresse Social dos Camundongos Swiss Submissos}

Os camundongos submissos foram enumerados de 1 até 16 para a realização do Teste do Estresse Social, sendo calculado a média de ataques sofridos durante o período de 10 dias. A média de ataques recebidos foi de 10,375 de cada camundongo ao longo dos 10 dias de Protocolo.

\section{Teste do Nado Forçado 2}

O segundo Teste do Nado Forçado foi realizado após o Protocolo de Estresse Social. Nesse teste, cada camundongo também foi monitorado individualmente e as informações tabeladas no Kinoscope. A média de 
tempo de Imobilidade foi de 149,8428 segundos $(131,134-179,485)$, sendo essa maior que as outras ações dos camundongos no decorrer do teste (Gráfico 2), o tempo estudado foram os 4 minutos, havendo 2 minutos iniciais de adaptação dos animais ao procedimento. Durante o estudo, foram identificados, além da Imobilidade, outras ações de Escalada, com média de 63,9551 segundos $(30,775$ - 88,332) e a Natação, com média de 26,2021 segundos $(4,063-62,378)$.

\section{Teste do Nado Forçado 2}

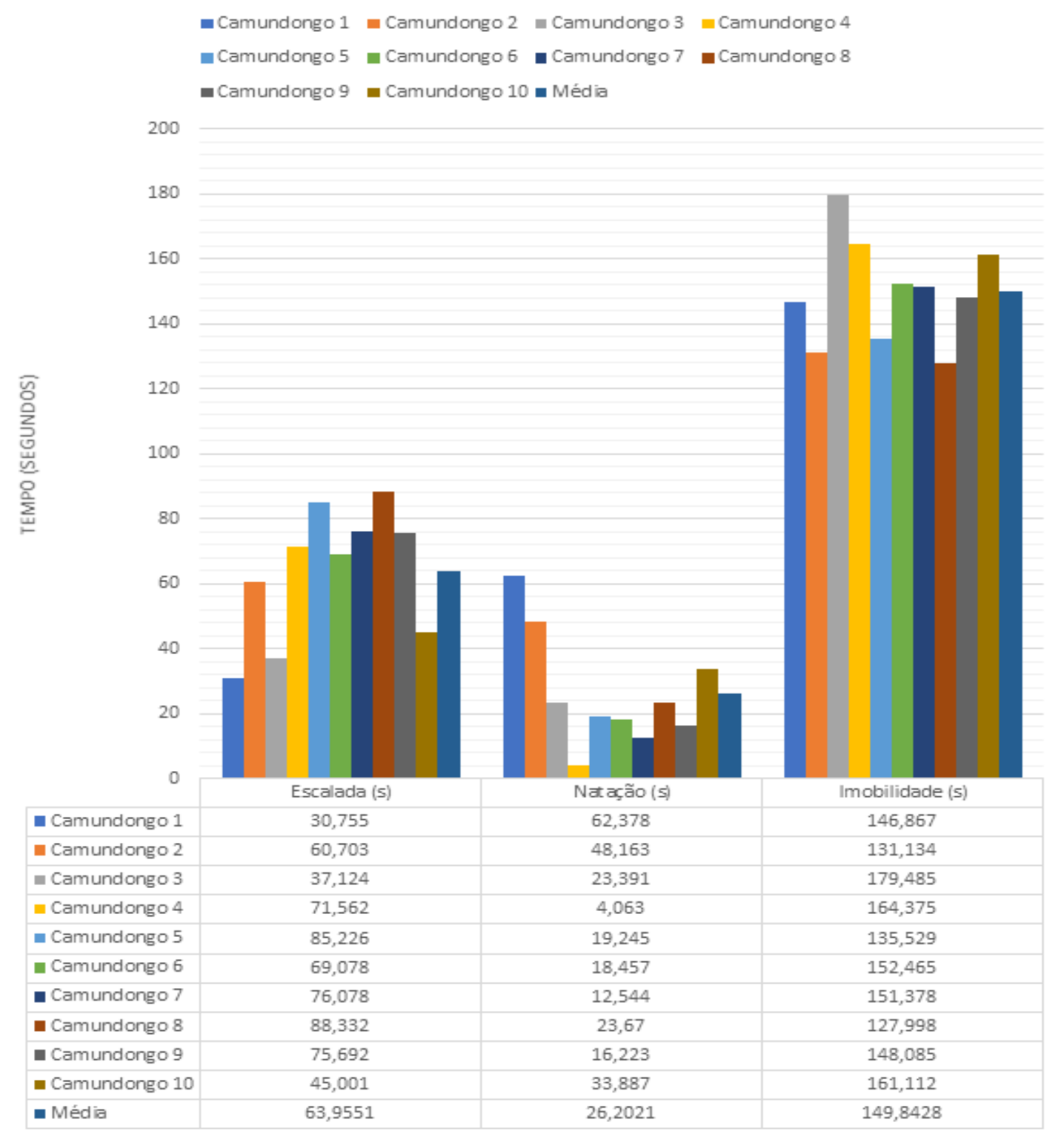

Gráfico 2. Segundo Teste do Nado Forçado, pré-operação.

\section{Procedimento Neurocirúrgico}

Foram realizados 12 procedimentos neurocirúrgicos, usando à sutura lambdóide como guia para à craniotomia e manuseio do estereotaxímetro para inoculação do GRP (Figura 1). Em todos os camundongos foram 
encontrados essa sutura bem delimitada e de fácil localização após exposição do crânio.

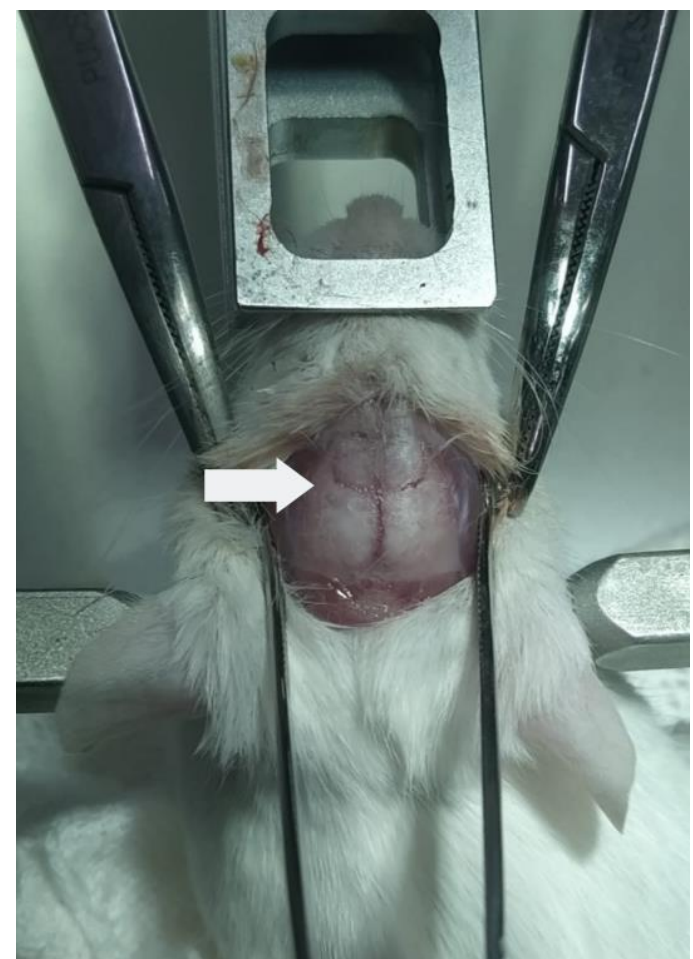

Figura 1. Vista do crânio superior do camundongo após secção cirúrgica e exposição da sutura lambdóide (seta) para craniotomia e injeção de GRP.

\section{Teste do Nado Forçado 3 - Grupo Experimental}

O terceiro Teste do Nado Forçado foi realizado após o procedimento neurocirúrgico. Nesse teste, cada camundongo também foi monitorado individualmente e as informações tabeladas no Kinoscope. A média de tempo de Imobilidade foi de 63,198 segundos $(56,981-69,415)$, o tempo estudado foram os 4 minutos, havendo 2 minutos iniciais de adaptação dos animais ao procedimento. Durante o estudo, foram identificados, além da Imobilidade, outras ações de Escalada, com média de 110,112 segundos $(89,021$ - 131,204) e a Natação, com média de 66,689 segundos $(39,381$ $93,998)$. 


\section{Teste do Nado Forçado 3}

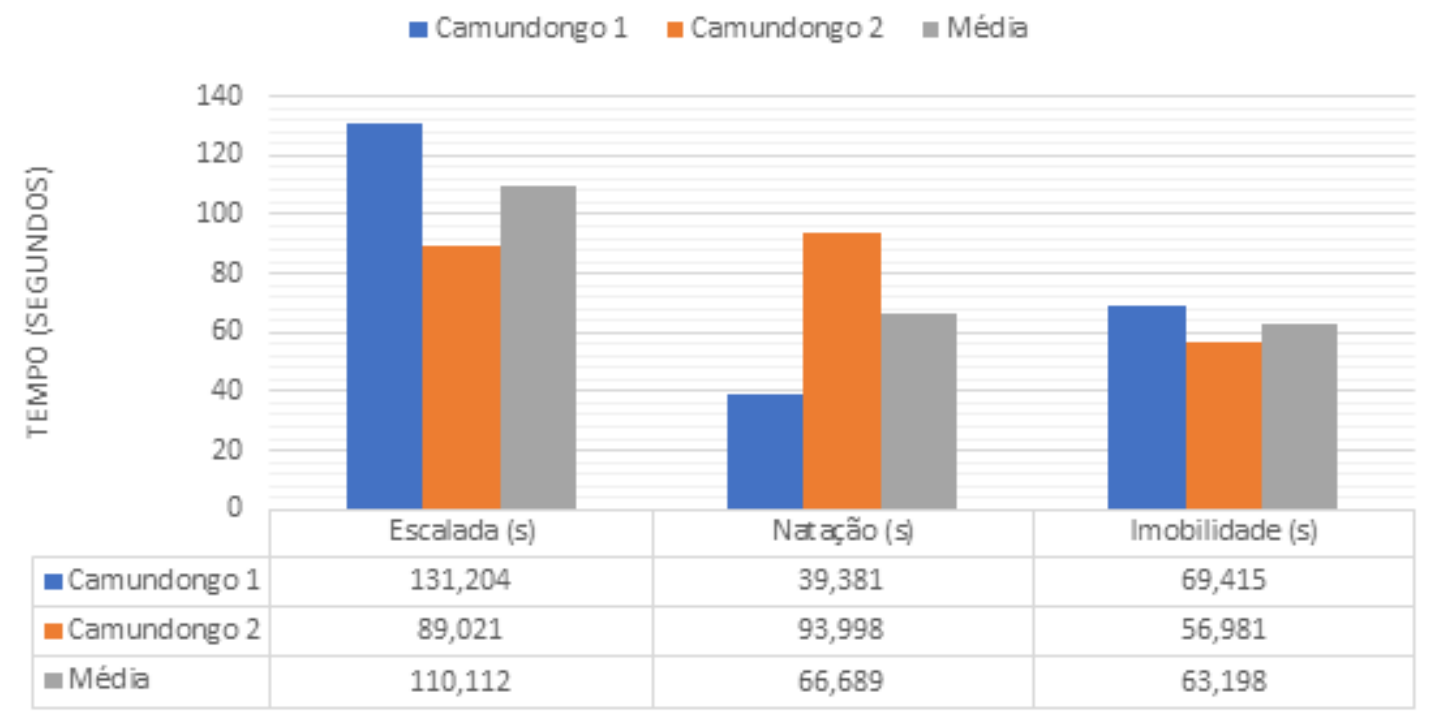

Gráfico 3. Terceiro Teste do Nado Forçado, pós-operação e injeção de GRP via nucleus accumbens.

\section{Teste do Nado Forçado 4 - Grupo Controle}

O quarto Teste do Nado Forçado foi realizado após a injeção de Fluoxetina no grupo controle. Nesse teste, cada camundongo também foi monitorado individualmente e as informações tabeladas no Kinoscope. A média de tempo de Imobilidade foi de 142,3025 segundos $(134,884-154,236)$, o tempo estudado foram os 4 minutos, havendo 2 minutos iniciais de adaptação dos animais ao procedimento. Durante o estudo, foram identificados, além da Imobilidade, outras ações de Escalada, com média de 59,999 segundos $(50,703$ - 76,205) e a Natação, com média de 38,6985 segundos $(28,911-54,087)$. 


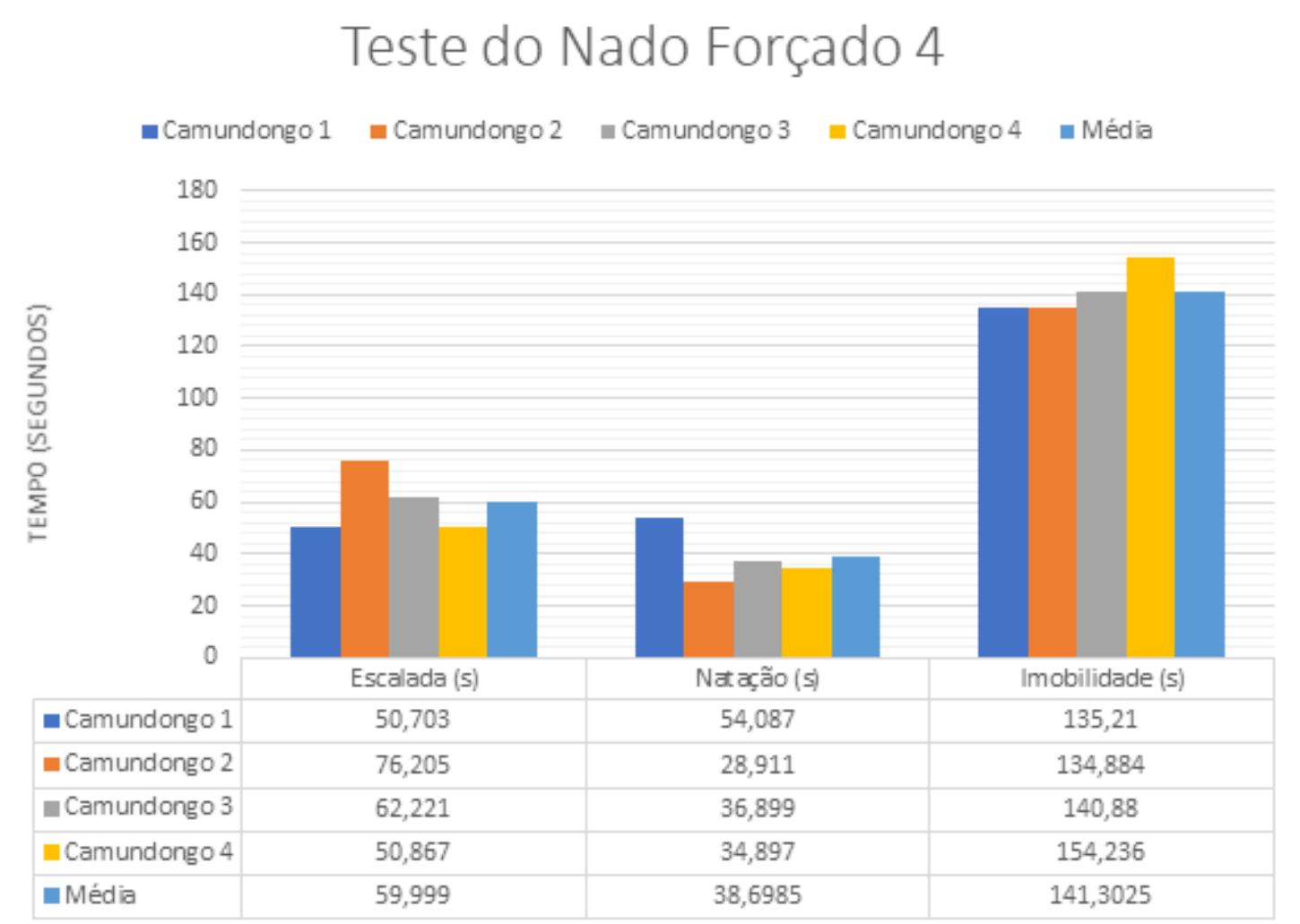

Gráfico 4. Quarto Teste do Nado Forçado, após a injeção de Fluoxetina

\section{Discussão}

$\mathrm{Na}$ análise desse estudo, foram encontrados resultados com impacto positivo no transtorno depressivo dos camundongos, mesmo em relação ao grupo controle. As literaturas mais recentes mostram que os receptores de GRP (GRPR) estão aumentados nas áreas do hipotálamo em situações de estresse e depressão, ainda sem precisão sobre o real efeito do GRP nesses receptores e os efeitos de neuroplasticidade no quadro depressivo [32].

Em relação aos outros hormônios estudados, o hormônio GRP apresentou efeitos positivos sobre o comportamento depressivo. Junto a ele está o Neuropeptídeo Y com sua ação no hipocampo e hipotálamo, que tem sua relação com à resiliência ao estresse e comportamento afetivo, reduzindo seu efeito em situação de depressão; ademais, o hormônio liberador de corticotrofina (CRH) também está reduzido na depressão e melhorou a anedonia induzida por estresse em ratos. Por outro lado, hormônios como Substância P, CCK, Galanina e TRH possuem efeito depressivo e ação

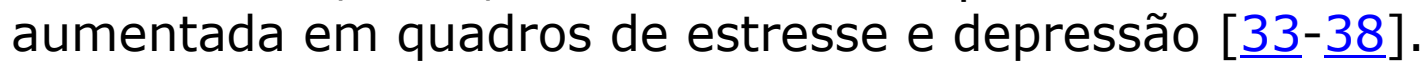

Os resultados desse estudo foram condizentes com a literatura, o que por sua vez dá mais indícios para que haja novos estudos relacionando 18 Debates em Psiquiatria, Rio de Janeiro, 2021; 11:1-26 
hormônios do trato gastrointestinal com distúrbios psiquiátricos. Assim, a aplicação em modelos de depressão é um passo importante para a fase clínica que possa vir a ser estabelecida futuramente.

O protocolo de derrota social utilizado aumentou em 13 segundos o tempo médio do nado forçado, conforme o esperado, tendo em consideração à análise de 4 minutos finais do TNF. Outros estudos obtiveram aumento de maior de tempo em testes mais longos, o que condiz com os resultados desse estudo [38]. Após o protocolo, o grupo dos animais operados teve uma melhora de 63 segundos no teste do nado forçado, o que demonstrou uma variação de 78 segundos em relação ao grupo controle tratado com fluoxetina.

Com isso, é possível inferir que, apesar do número baixo de animais operados, o GRP pode ter um papel importante no circuito de Papez, responsável pelo processamento cerebral do comportamento, onde o Núcleo Accumbens possui bastante relevância. [39 , 40] Atrelado a isso, uma vez que esse tema está começando a ser elucidado geneticamente e patologicamente nos tempos atuais, outra relação em hipótese é que o GRPR está aumentado em áreas de estresse no sistema límbico e circuito de Papez. [41] Tal projeto realizado obteve resultados positivos em modelos Webster de depressão por meio da Derrota Social, promovendo uma etapa seguinte de estudos in vitro atuais; [41] o que arcabouça mais a relação do GRP com a depressão, uma vez que já é possível ver efeitos terapêuticos na prática pré-clínica do tema.

Um viés deste estudo, que deve ser considerado, foi o baixo número de camundongos Swiss no grupo experimental devido a mortes durante a anestesia pré-neurocirurgia $(\mathrm{N}=2)$. Embora seguindo protocolos já estabelecidos sobre a quantidade de cada anestésico a ser injetado, houve camundongos que necessitavam de doses maiores para sedação, não havendo outro parâmetro para não quantificar a dose de anestésico arbitrariamente. Assim, houve perda de uma parte do grupo experimental.

\section{Conclusão}

Em geral, este estudo confirmou a relação do hormônio GRP com o Nucleus Accumbens e melhora em quadros depressivos. Além disso, há amostras experimentais da interação do GRP com a melhora do comportamento e imobilidade de camundongos Swiss. Assim, os resultados obtidos destacam o envolvimento do GRP como novo alvo biológico a ser estudado para terapia contra a depressão. 


\section{Referências}

1. Belujon P, Grace AA. Dopamine system dysregulation in major depressive disorders. Int J Neuropsychopharmacol. 2017;20(12):1036-46. https://doi.org/10.1093/ijnp/pyx056 PMid:29106542 - PMCid:PMC5716179

2. Drevets WC, Price JL, Furey ML. Brain structural and functional abnormalities in mo-od disorders: Implications for neurocircuitry models of depression. Brain Struct Funct. 2008;213(1-2):93-118. https://doi.org/10.1007/s00429-008-0189-x - PMid:18704495 PMCid:PMC2522333

3. Francis TC, Lobo MK. Emerging Role for Nucleus Accumbens Medium Spiny Neuron Subtypes in Depression. Biol Psychiatry [Internet]. 2016;81(8):645-53.

https://doi.org/10.1016/j.biopsych.2016.09.007 - PMid:27871668 PMCid:PMC5352537

4. Hendrickx H, McEwen BS, Ouderaa F Van Der. Metabolism, mood and cognition in aging: The importance of lifestyle and dietary intervention. Neurobiology of Aging. 2005; 26(1):1-5, Supplement, https://doi.org/10.1016/j.neurobiolaging.2005.10.005

5. Flor LS, Campos MR. Prevalência de diabetes mellitus e fatores associados na população adulta brasileira: evidências de um inquérito de base populacional. Rev Bras Epidemiol [Internet]. 2017;20(1):16-29. https://doi.org/10.1590/19805497201700010002 - PMid:28513791

6. Wexler DJ, Porneala B, Chang Y, Huang ES, Huffman JC, Grant RW. Diabetes differentially affects depression and selfrated health byage in the U.S. Diabetes Care. 2012;35(7):1575-7. https://doi.org/10.2337/dc11-2266 - PMid:22611066 PMCid:PMC3379579

7. Villanueva R. Neurobiology of Major Depressive Disorder.

Psychosom Med. 2013;2013(2013):1-7. https://doi.org/10.1155/2013/873278 - PMid:24222865 PMCid:PMC3810062 
8. Grippo AJ, Johnson AK. Stress, depression and cardiovascular dysregulation: A review of neurobiological mechanisms and the integration of research from preclinical disease models. Stress. 2009;12(1):1-21. https://doi.org/10.1080/10253890802046281 PMid:19116888 - PMCid:PMC2613299

9. Rohleder N, Schommer NC, Hellhammer DH, Engel R, Kirschbaum C. Sex differences in glucocorticoid sensitivity of proinflammatory cytokine production after psychosocial stress. Psychosom Med. 2001;63(6):966-72. https://doi.org/10.1097/00006842200111000-00016 - PMid:11719636

10. Lutter M, Nestler EJ. Homeostatic and Hedonic Signals Interact in the Regulation of Food Intake. J Nutr [Internet]. 2009 Mar 1;139(3):629-32. https://doi.org/10.3945/jn.108.097618 PMid:19176746 PMCid:PMC2714382

11. O'Kushky J, Ye P. Neurodevelopmental effects of insulin-like growth factor signaling. Front Neuroendocrinol. 2012;33(3):230-51. https://doi.org/10.1016/j.yfrne.2012.06.002 - PMid:22710100 PMCid:PMC3677055

12. Malberg JE, Platt B, Rizzo SJS, Ring RH, Lucki I, Schechter LE, Rosenzweig-Lipson S. Increasing the levels of insulin-like growth factor-I by an IGF binding protein inhibitor produces anxiolytic and antidepressant-like effects. Neuropsychopharmacology. 2007; 32(11):2360-8. https://doi.org/10.1038/sj.npp.1301358 PMid: 17342171

13. Hoshaw BA, Malberg JE, Lucki I. Central administration of IGF-I and BDNF leads to long-lasting antidepressant-like effects. Brain Res. $2005 ; 1037(1-2): 204-8$. https://doi.org/10.1016/j.brainres.2005.01.007 - PMid:15777771

14. Becker C, Zeau B, Rivat C, Blugeot A, Hamon M, Benoliel J]. Repeated social defeat-induced depression-like behavioral and biological alterations in rats: Involvement of cholecystokinin. Mol Psychiatry. 2008;13(12):1079-92.

https://doi.org/10.1038/sj.mp.4002097 - PMid:17893702 
15. Vialou V, Bagot RC, Cahill ME, Ferguson D, Robison AJ, Dietz DM, et al. Prefrontal Cortical Circuit for Depression and AnxietyRelated Behaviors Mediated by Cholecystokinin: Role of FosB. J Neurosci [Internet]. 2014;34(11):3878-87. https://doi.org/10.1523/JNEUROSCI.1787-13.2014 PMid:24623766 PMCid:PMC3951691

16. Del Boca C, Lutz PE, Le Merrer J, Koebel P, Kieffer BL. Cholecystokinin knockdown in the basolateral amygdala has anxiolytic and antidepressant-like effects in mice. Neuroscience [Internet]. 2012 Aug 12;218(9):185-95.

https://doi.org/10.1016/j.neuroscience.2012.05.022 PMid:22613736 - PMCid:PMC3532740

17. Schwartsmann G, Henriques J, Roesler R. Gastrin-Releasing Peptide Receptor as a Molecular Target for Psychiatric and Neurological Disorders. CNS \& Neurol Disord - Drug Targets [Internet]. 2006;5(2):197-204. https://doi.org/10.2174/187152706776359673 PMid: 16611092

18. Yao L, Chen J, Chen $H$, Xiang D, Yang C, Xiao L, Liu W, Wang $H$, Wang G, Zhu F, Liu Z. Hypothalamic gastrin-releasing peptide receptor mediates an antidepressant-like effect in a mouse model of stress. Am J Transl Res [Internet]. 2016;8(7):3097-105. PMID: 27508030 - PMCID: PMC4969446.

19. Monje FJ, Kim E-J, Cabatic M, Lubec G, Herkner KR, Pollak DD. A role for glucocor-ticoid-signaling in depression-like behavior of gastrin-releasing peptide receptor knock-out mice. Annals of Med [Internet]. 2011;43(5):389-402.

https://doi.org/10.3109/07853890.2010.538716 - PMid:21254899

20. Roesler R, Kent P, Luft T, Schwartsmann G, Merali Z. Gastrinreleasing peptide receptor signaling in the integration of stress and memory. Neurobiol Learn Mem [Internet]. 2014;112:44-52. https://doi.org/10.1016/j.nIm.2013.08.013 - PMid:24001571

21. Flood JF, Morley JE. Effects of bombesin and gastrin-releasing peptide on memory processing. Brain Res. 1988;460(2):314-22. https://doi.org/10.1016/0006-8993(88)90375-7 
22. Merali Z, Kent P, Du L, Hrdina P, Palkovits M, Faludi G, Poulter MO, Bédard T, Anisman $\mathrm{H}$. Corticotropin-releasing hormone, arginine vasopressin, gastrin-releasing peptide, and neuromedin B alterations in stress-relevant brain regions of suicides and control subjects. Biol Psychiatry. 2006;59(7):594-602.

https://doi.org/10.1016/j.biopsych.2005.08.008 - PMid:16197926

\section{Merali Z, Anisman H, James JS, Kent P, Schulkin J. Effects of} corticosterone on corticotrophin-releasing hormone and gastrinreleasing peptide release in response to an aversive stimulus in two regions of the forebrain (central nucleus of the amygdala and prefrontal cortex). Eur J Neurosci. 2008;28(1):165-72.

https://doi.org/10.1111/j.1460-9568.2008.06281.x PMid: 18662341

24. Iniguez SD, Aubry A, Riggs LM, Alipio JB, Zanca RM, FloresRamirez FJ, Hernandez MA, Nieto, SJ, Musheyev D, Serrano PA. Social defeat stress induces depression-like behavior and alters spine morphology in the hip-pocampus of adolescent male C57BL/6 mice. Neurobiol Stress. 2016;5:54-64.

https://doi.org/10.1016/j.ynstr.2016.07.001 - PMid:27981196 PMCid:PMC5154707

25. Riggs LM, Nieto SJ, Dayrit G, Zamora NN, Shawhan KL, Cruz B, Warren BL. Social defeat stress induces a depression-like phenotype in adolescent male c57BL/6 mice. HHS Public Access.

2014;17(3):247-55.

https://doi.org/10.3109/10253890.2014.910650 - PMid:24689732 PMCid:PMC5534169

26. Stepanichev M, Dygalo NN, Grigoryan G, Shishkina GT, Gulyaeva N. Rodent models of depression: Neurotrophic and neuroinflammatory biomarkers. Biomed Res Int. 2014;2014. https://doi.org/10.1155/2014/932757 - PMid:24999483 PMCid:PMC4066721

27. Tsankova NM, Berton O, Renthal W, Kumar A, Neve RL, Nestler EJ. Sustained hip-pocampal chromatin regulation in a mouse model of depression and antidepressant action. Nat Neurosci. 2006;9(4):519-25. https://doi.org/10.1038/nn1659 PMid: 16501568 
28. Nikolaos Kokras, Dimitrios Baltas, Foivos Theocharis, Christina Dalla. Kinoscope: An Open-Source Computer Program for Behavioral Pharmacologists. Front Behav Neu-rosci | www.frontiersin.org [Internet]. 2017 [citado 25 de agosto de 2019];11(88):1-7. https://doi.org/10.3389/fnbeh.2017.00088 - PMid:28553211 PMCid:PMC5427106

29. Nicotine Exposure during Adolescence Induces a Depression-Like State in Adulthood. Neuropsychopharmacology [Internet]. 2009 May 17;34(6):1609-24. https://doi.org/10.1038/npp.2008.220 PMid:19092782 - PMCid:PMC2692426

30. Qi J, Zhang S, Wang H, Barker DJ, Miranda-Barrientos J, Morales $M$. VTA glutama-tergic inputs to nucleus accumbens drive aversion by acting on GABAergic interneu-rons. Nat Neurosci [Internet]. 2016 May 28;19(5):725-33. https://doi.org/10.1038/nn.4281 PMid:27019014 - PMCid:PMC4846550

\section{El-Din AG, Aly MA, Ramadan MA, Mostafa M, Hamed} SM. Behavioral Monitoring Tool. Egypt; 2011. Available at: http://ratmonitoring.sourceforge.net/\#

32. Xiang D, Wang $H$, Sun $S$, Yao L, Li R, Zong X, Wang G, Liu Z. GRP Receptor Regulates Depression Behavior via Interaction With 5HT2a Receptor. Front Psychiatry. 2020;10(January):1-9. https://doi.org/10.3389/fpsyt.2019.01020 - PMid:32047449 PMCid:PMC6997338

33. Wang $P$, Li $H$, Barde $S$, Zhang MD, Sun J, Wang $T$, Zhang $P$, Luo $\mathrm{H}$, Wang $\mathrm{Y}$, Yang $\mathrm{Y}$, Wang $\mathrm{C}$, Svenningsson $\mathrm{P}$, Theodorsson $\mathrm{E}$, Hokfelt TGM, Xu ZQD. Depression-like behavior in rat: Involvement of galanin receptor subtype 1 in the ventral periaqueductal gray. Proc Natl Acad Sci U S A. 2016;113(32):E4726-35. https://doi.org/10.1073/pnas.1609198113 - PMid:27457954 PMCid:PMC4987783

34. Prakash N, Stark CJ, Keisler MN, Luo L, Der-Avakian A, Dulcis D. Serotonergic plas-ticity in the dorsal raphe nucleus characterizes susceptibility and resilience to anhedo-nia. J Neurosci. 2020;40(3):569-84. https://doi.org/10.1523/JNEUROSCI.180219.2019 - PMid:31792153 - PMCid:PMC6961996 
35. Savanthrapadian S, Meyer T, Elgueta C, Booker SA, Vida I, Bartos M. Synaptic properties of SOM-and CCK-expressing cells in dentate gyrus interneuron networks. J Neurosci. 2014;34(24):8197209. https://doi.org/10.1523/JNEUROSCI.5433-13.2014 PMid:24920624 - PMCid:PMC6608234

36. Hassan AM, Mancano G, Kashofer K, Fröhlich EE, Matak A, Mayerhofer R, Reichmann F, Olivares M, Neyrinck AM, Delzenne NM, Claus SP, Holzer P. High-fat diet induces depression-like behaviour in mice associated with changes in microbiome, neuropeptide $Y$, and brain metabolome. Nutr Neurosci. 2019;22(12):877-93. https://doi.org/10.1080/1028415X.2018.1465713 - PMid:29697017

37. Vialou V, Bagot RC, Cahill ME, Ferguson D, Robison AJ, Dietz DM, Fallon B, Mazei-Robison M, Ku SM, Harrigan E, Winstanley CA, Joshi T, Feng J, Berton O, Nestler EJ. Prefrontal cortical circuit for depression- and anxiety-related behaviors mediated by cholecystokinin: Role of $\triangle$ FosB. J Neurosci. 2014;34(11):3878-87. https://doi.org/10.1523/JNEUROSCI.1787-13.2014 PMid:24623766 PMCid:PMC3951691

38. Choi J, Kim JE, Kim TK, Park JY, Lee JE, Kim H, Lee EH, Han PL. $\mathrm{TRH}$ and TRH receptor system in the basolateral amygdala mediate stress-induced depression-like behaviors. Neuropharmacology [Internet]. 2015;97:346-56. https://doi.org/10.1016/j.neuropharm.2015.03.030 PMid:26107116

39. Witzmann FA, Li J, Strother WN, McBride WJ, Hunter L, Crabb $D W$, Lumeng $L$, Li TK. Innate differences in protein expression in the nucleus accumbens and hippocampus of inbred alcohol-preferring and -nonpreferring rats. In: Proteomics [Internet]. Proteomics; 2003 [citado 4 de outubro de 2020]. p. 1335-44. https://doi.org/10.1002/pmic.200300453 - PMid:12872235 PMCid:PMC2652869

40. Kramer DJ, Risso D, Kosillo P, Ngai J, Bateup HS. Combinatorial expression of Grp and Neurod6 defines dopamine neuron populations with distinct projection patterns and disease vulnerability. eNeuro [Internet]. 1 de maio de 2018 [citado 4 de outubro de 2020];5(3). 
https://doi.org/10.1523/ENEURO.0152-18.2018 - PMid:30135866 PMCid:PMC6104179

41. Xiang D, Wang H, Sun S, Yao L, Li R, Zong X, Wang G, Liu Z.

GRP Receptor Regulates Depression Behavior via Interaction With 5HT2a Receptor. Front Psychiatry. 2020;10(January):1-9. https://doi.org/10.3389/fpsyt.2019.01020 - PMid:32047449 PMCid:PMC6997338

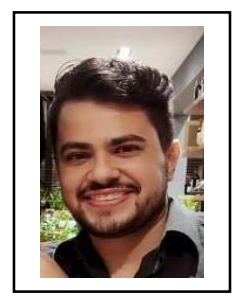

Rodrigo de Almeida

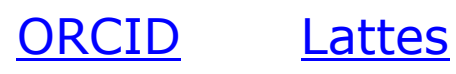

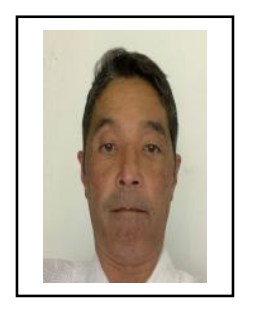

Jorge Henna Neto

$\underline{\text { ORCID Lattes }}$

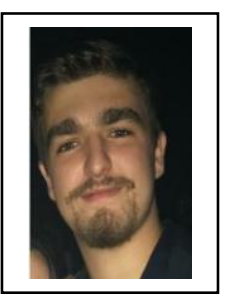

Eduardo Ernani Piazza da Silva

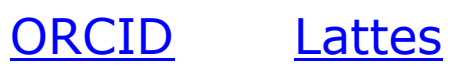

